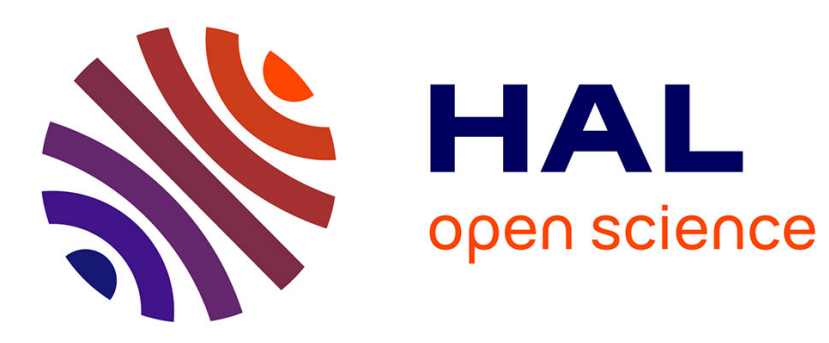

\title{
High current permanent discharges in air induced by femtosecond laser filamentation
}

\author{
Aurélien Houard, Ciro d'Amico, Yi Liu, Yves-Bernard André, Michel Franco, \\ Bernard Prade, André Mysyrowicz, Estelle Salmon, Pascal Pierlot, L.-M.
}

Cleon

\section{To cite this version:}

Aurélien Houard, Ciro d'Amico, Yi Liu, Yves-Bernard André, Michel Franco, et al.. High current permanent discharges in air induced by femtosecond laser filamentation. Applied Physics Letters, 2007, 90 (17), pp.171501. 10.1063/1.2734396 . hal-00454781

\section{HAL Id: hal-00454781}

https://hal-polytechnique.archives-ouvertes.fr/hal-00454781

Submitted on 1 Mar 2010

HAL is a multi-disciplinary open access archive for the deposit and dissemination of scientific research documents, whether they are published or not. The documents may come from teaching and research institutions in France or abroad, or from public or private research centers.
L'archive ouverte pluridisciplinaire HAL, est destinée au dépôt et à la diffusion de documents scientifiques de niveau recherche, publiés ou non, émanant des établissements d'enseignement et de recherche français ou étrangers, des laboratoires publics ou privés. 


\title{
High current permanent discharges in air induced by femtosecond laser filamentation
}

\author{
A. Houard, C. D’Amico, Y. Liu, Y. B. Andre, M. Franco, B. Prade, A. Mysyrowicz \\ Laboratoire d'Optique Appliquée, ENSTA, Ecole Polytechnique, CNRS UMR 7639, 91761, Palaiseau, \\ France \\ E. Salmon \\ LASIM, Université Lyon 1, CNRS UMR 5579, 69622, Villeurbanne, France \\ P. Pierlot, L.-M. Cleon \\ Agence d'Essai Ferroviaire, SNCF, 21 Av du Président Allende, 94407, Vitry-sur-Seine, France
}

\begin{abstract}
Filaments created in air by an intense femtosecond laser pulse in the presence of an electric field generate a highly conductive permanent plasma column. (C) 2007 American Institute of Physics.
\end{abstract}

There is currently a wide interest in the process of femtosecond laser filamentation in air (For a recent review see ${ }^{1}$ ). During its propagation in air, an intense short IR laser pulse first undergoes self-focusing, because of the optical Kerr effect, until the peak intensity on axis becomes high enough $\left(\sim 5^{*} 10^{13} \mathrm{~W} / \mathrm{cm}^{2}\right)$ to ionize air molecules. The ionization process involves the simultaneous absorption of 8-10 infrared photons. It has therefore a threshold like behaviour and a strong clamping effect on the intensity in the self guided pulse. A dynamical competition then starts taking place between the self-focusing effect due to the optical Kerr effect and the defocusing effect due to the created plasma. As a result, the pulse maintains a small beam diameter and high peak intensity over large distances. In the wake of the selfguided pulse, a plasma column is created with an initial density of $10^{16}-10^{17}$ electrons $/ \mathrm{cm}^{3}$ over a distance which depends on initial laser conditions. This length is typically one meter for a pulse initial power close to the minimum value $\mathrm{P}_{\mathrm{cr}}$ required for filamentation ( $5 \mathrm{GW}$ for an IR pulse at $800 \mathrm{~nm}$ under normal air conditions) and can reach hundreds of meters at higher powers.

It has been demonstrated that this plasma column is able to trigger and guide high voltage electric discharges between two electrodes in contact with the plasma column. ${ }^{2-3}$ Remarkably, there is a noticeable delay between the arrival of the laser pulse and the initiation of the discharge. A model has been developed which reproduces quantitatively this delayed initiation of the discharge in laboratory experiments. ${ }^{2}$ In short, the short-lived plasma leads, in the presence of an electric field, to Joule heating of a thin air column. After plasma recombination, the expansion of the heated air column leads to a central depression canal, which initiates and guides the electric discharge. Up to 4 meters long electric discharges have been produced with MV applied voltage. ${ }^{4-6}$ Although many features of these long discharges were similar to those carried on a $\mathrm{cm}$ scale in the laboratory, and therefore point out to a similar thermally driven discharge initiation, the more complex boundary conditions of the experiment prevented meaningful simulations to test the model.

There are many potential applications of filament-triggered discharges (laser lightning rod, fast switch for high voltage connection, etc.). In this letter, we address another potential application, namely the contactless capture of current. A crucial requirement for such an application is the resistivity of the produced plasma, which must remain low in order to minimize unwanted power dissipation. Other important questions concern the amount of current such a discharge is able to carry, and the plasma lifetime, which should be long enough so that the plasma column is sustained between successive laser shots even at a low repetition rate. In order to address these questions, experiments have been performed using the Teramobile laser in conjunction with electric power facility designed to test the motors of highspeed trains (TGV).

The Teramobile laser is a mobile CPA (Chirp Pulse Amplification) laser system based on Titanium:Sapphire technology delivering pulses of $100 \mathrm{fs}$ duration, with a peak power of several TW and a repetition rate of $10 \mathrm{~Hz}$. $^{7} \mathrm{The}$ laser beam was focused in air with a telescope of $25 \mathrm{~m}$ focal length. This led to the formation of a bundle of about 40 plasma filaments over a distance of $\sim 5 \mathrm{~m}$. Two electrodes consisting of cylindrical copper blocks of $3 \mathrm{~cm}$ diameter were placed 2 meters beyond the beginning of the filaments. At this point the diameter of the filament bundle was $\sim 7 \mathrm{~mm}$. It crossed through a $5 \mathrm{~mm}$ diameter hole pierced in the first electrode and impinged on the second electrode. The distance between the two electrodes could be varied between 3 and $60 \mathrm{~mm}$. In some experiments, both electrodes were pierced, letting the filament bundle through, with no significant change in the results. The electric voltage applied across the electrodes was either DC voltage of $4 \mathrm{kV}$ or $\mathrm{AC}$ of $20 \mathrm{kV}$. In all measurements, we checked that no spontaneous discharge occurred in the absence of a laser pulse. The current flowing through the plasma when triggered by the laser generated filaments was measured with a coaxial shunt.

Experiments were also carried out with a first electrode hole diameter of 4 and $3 \mathrm{~mm}$ with no significant change in the results. However, we could not reach the limit of a single filament because of alignment difficulties.

E-mail address: andre.mysyrowicz@ensta.fr 
A typical result in the case of a $3 \mathrm{kV}$ DC voltage is shown in Figure 2(a) for an electrode separation of $4 \mathrm{~mm}$. One notices a sudden drop (within the detection time resolution $\sim 2 \mathrm{~ms}$ ) of the voltage across the electrodes while simultaneously the current reaches $250 \mathrm{~A}$, the maximum value allowed by the power supply. The power dissipation in the plasma was around $8 \mathrm{~kW}$, yielding an ohmic resistance of less than $0.1 \Omega / \mathrm{cm}$. This high conductivity is maintained for the duration of the applied voltage (1.2 s). If the voltage is applied for a longer duration, melting of the electrodes occurs. The melting is accompanied by a thermally driven displacement of the plasma to the top of the electrodes. In this case, the dissipation in the discharge increases significantly, as shown in Figure 2(b). A triggering rate of $80 \%$ was obtained for several hundreds of attempts. In no case, a spontaneous discharge occurred in the absence of a laser shot.

Experiments were also carried out with AC voltage. Figure 3(a) shows the current flowing through the electrodes with a peak voltage of $20 \mathrm{kV}$ at $50 \mathrm{~Hz}$. After the onset of filamentation, the applied voltage drops to near zero and a 50 $\mathrm{Hz}$ alternative current flows between the electrodes. The high conducting discharge could be obtained over a distance of up to $6 \mathrm{~cm}$, with a peak current again limited by the power supply. The average power dissipation in the AC mode was $8000 \mathrm{~W}$ for a current of 8.9 A RMS, yielding an average resistance $R / l \sim 25 \Omega / \mathrm{cm}$. Triggering of the discharge occurred preferentially when the negative voltage crest was synchronous with the laser pulse. Triggering on the positive crest was also observed, but with less statistical success. In some instances, we observed the discharge occurring at the peak of the negative crest while the laser was coincident with the positive crest (see Figure 3(b)).

To discuss the results we first note that the applied voltage obviously converts the initial cold, low-density plasma into a high conducting, high temperature and long-lived plasma column. One can estimate the final plasma temperature by noting that in order to account for the measured plasma resistance, one must assume that all molecules in air become singly ionized. In this case, the plasma conductivity $\sigma\left(\Omega^{-1} \cdot \mathrm{cm}^{-1}\right)$ can be expressed with the Spitzer formula: ${ }^{8}$

$$
\sigma=\frac{l}{R \times S}=\frac{n_{e} e^{2}}{m_{e} v_{e i}}=1.53 \times 10^{-4} \frac{T_{e}^{3 / 2}}{Z \ln \Lambda},
$$

where $n_{e}$ is the electron density, $v_{e i}$ the electron-ion collision frequency, $T_{e}$ is the electronic temperature (in $\mathrm{K}$ ) and $\ln \Lambda$ is the Coulomb logarithm:

$$
\ln \Lambda=23-\ln \left(\frac{Z \sqrt{n_{e}}}{\left(T_{e}\right)^{3 / 2}}\right) .
$$

For $\mathrm{n}_{\mathrm{e}}=10^{19} \mathrm{~cm}^{-3}, \mathrm{Z}=1, \mathrm{~S}=2 \mathrm{~cm}^{2}$ and $R / l=0.17 \Omega \cdot \mathrm{cm}^{-1}$, we obtain a temperature $\mathrm{T}_{\mathrm{e}}=3.5 \times 10^{4} \mathrm{~K} \sim 3 \mathrm{eV}$.

Concerning the kinetics of plasma evolution, from a low-density initial plasma $\left(\mathrm{n}_{\mathrm{e}} \sim 10^{16}-10^{17} \mathrm{~cm}^{-3}\right)$ to a fully ionized plasma, we note that in some instances the discharge was observed with a significant delay $\mathrm{dt} \approx 10 \mathrm{~ms}$ (see figure 3(b)). We therefore tentatively attribute the initiation of the discharge to the same mechanism as discussed in ref. 3 , namely a thermally induced effect.

In conclusion, the plasma generated by femtosecond laser filaments has a low ohmic resistivity, and it is able to carry a large current, either DC or AC over a long time $>1 \mathrm{~s}$. These features are promising for applications such as the contactless capture of current.

We are grateful to Dr M. Pellet from DGA and to Dr Steffan Hüller for fruitful discussions.

\section{References:}

${ }^{1}$ A. Couairon and A. Mysyrowicz, Femtosecond filamentation in transparent media, Phys. Rep. 441, 47 (2007)

${ }^{2}$ S. Tzortzakis, M. Franco, Y.-B. André, A. Chiron, B. Lamouroux, B. Prade, A. Mysyrowicz, Phys. Rev. E rapid comm. 60, R3505 (1999)

${ }^{3}$ S. Tzortzakis, B. Prade, M. Franco, A. Mysyrowicz, S. Hüller, and P. Mora, Phys. Rev. E 64, 57401 (2001)

${ }^{4}$ M. Rodriguez, R. Sauerbrey, H. Wille, L. Wöste, T. Fujii, Y.-B. André, A. Mysyrowicz, J. Kasparian, E. Salmon, J. Yu, and J.-P. Wolf, Opt. Lett. 27, 772 (2002)

${ }^{5}$ R. Ackermann, G. Méchain, G. Méjean, R. Bourayrou, M. Rodriguez, K. Stelmaszczyk, J. Kasparian, J. Yu, E. Salmon, S. Tzortzakis, Y-B. André, J.-F. Bourrillon, L. Tamin, J.-P. Cascelli, C. Campo, C. Davoise, A. Mysyrowicz, R. Sauerbrey, L. Wöste, J.-P.Wolf., Appl. Phys. B 82, 561 (2006)

${ }^{6}$ R. Ackermann, K. Stelmaszczyk, P. Rohwetter, G. Mejean, E. Salmon, J. Yu, G. Mechain, J. Kasparian, V. Bergmann, S. Schaper, B. Weise, T. Kumm, K. Rethmeier, W. Kalkner, J.-P. Wolf, L. Wöste, Appl. Phys. Lett. 85, 23 (2004)

${ }^{7}$ H. Wille, M. Rodriguez, J. Kasparian, D. Mondelain, J. Yu, A. Mysyrowicz, R. Sauerbrey, J. P. Wolf, L. Wöste, Eur. Phys. J.: Appl. Phys. 20, 183$190(2002)$

${ }^{8}$ L. Spitzer, Physics of Fully Ionized Gases, Interscience Publishers, Inc., New York (1955) 


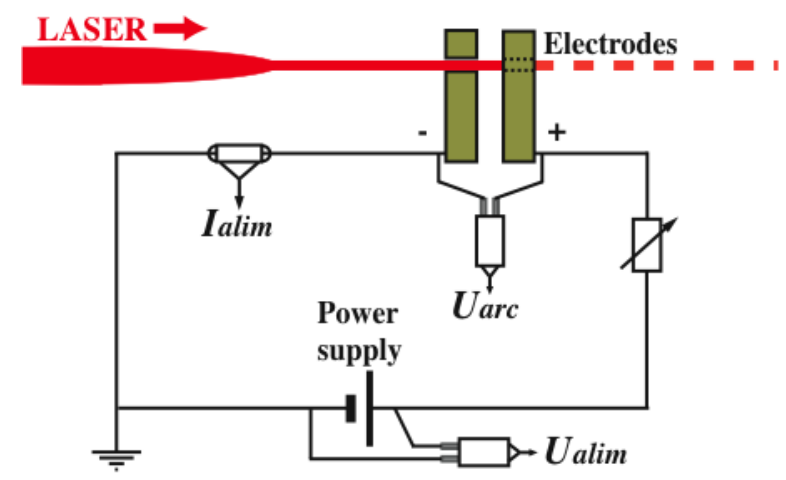

FIG. 1. Experimental set-up.
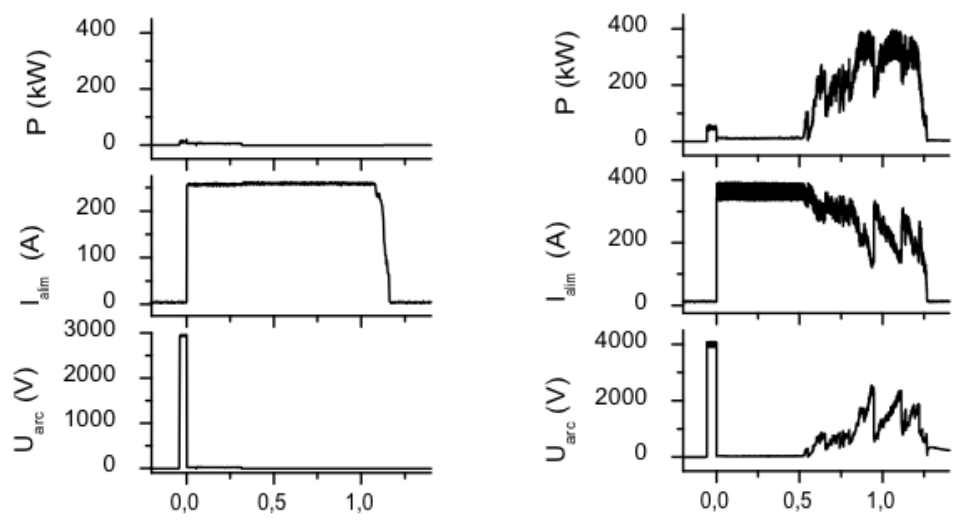

$\mathrm{t}$ (s)

a)

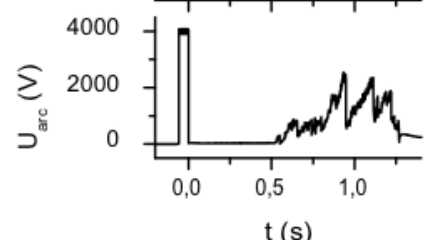

b)

FIG. 2. (a) Evolution of the voltage $\left(U_{\text {arc }}\right)$, current flowing $\left(I_{\text {alim }}\right)$ and dissipated power $(P)$ between the two electrodes. The voltage is applied during $1.5 \mathrm{~s}$ and the laser pulse arrived at $\mathrm{t}=0 \mathrm{~s}$. The current discharge is triggered by the laser filaments. (b) Evolution of the voltage $\left(U_{\text {arc }}\right)$, current flowing $\left(I_{\text {alim }}\right)$ and dissipated power $(P)$ between the electrodes when the guided discharge transforms into an $\operatorname{arc}($ at $\mathrm{t}=0.5 \mathrm{~s})$.
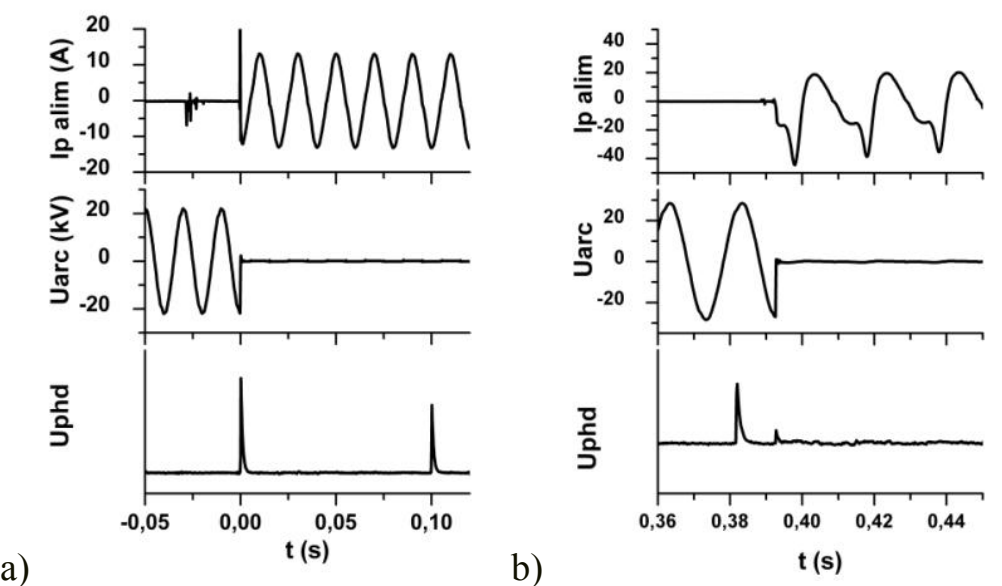

FIG. 3. (a) Evolution of the AC voltage across the electrodes $\left(U_{\text {arc }}\right)$ and current flowing between the electrodes $\left(I_{p}\right.$ alim). At the bottom the photodiode signal $\left(U_{P h D}\right)$ also gives the arrival time of the laser pulse on the electrode. Here $\mathrm{t}=0 \mathrm{~s}$ correspond to the formation of the trigger laser filament. (b) Same experiment but with a delay between the laser pulse and the discharge initiation. 